\title{
Effect of the Location of Hydrogen Abstraction on the Fragmentation of Diuretics in Negative Electrospray Ionization Mass Spectrometry
}

\author{
Mario Thevis and Wilhelm Schänzer \\ Institute of Biochemistry, German Sport University Cologne, Cologne, Germany \\ Hans Schmickler \\ Institute of Organic Chemistry, University of Cologne, Cologne, Germany
}

The diuretic agents bumetanide, xipamide, indapamide, and related compounds were investigated in order to determine the effect of different ionization sites on their collisionally activated dissociation and the corresponding fragmentation pathways. Therefore, analytes were selectively alkylated, and structural analogues as well as deuterium labeled compounds synthesized, which contain a reduced number of ionizable hydrogen atoms. Thus, specific hydrogen abstractions and their correlated dissociation routes of the negatively charged molecules were eliminated, providing evidence for the influence of the location of ionization on product ion spectra. Fragment ions such as $\mathrm{m} / \mathrm{z} 78$ indicate ionization at the commonly present sulfamoyl residue of diuretics but does not exclude additional ionization sites. Product ion spectra of the investigated diuretic agents proved to be composed by fragmentations initiated from different hydrogen abstractions. Moreover, the generation of radical anions by collision-activated dissociation of even-electron precursor ions was observed, the generation of which is discussed by proposed fragmentation pathways. (J Am Soc Mass Spectrom 2003, 14, 658-670) ( 2003 American Society for Mass Spectrometry

S ince the use of electrospray ionization interfaced to tandem mass spectrometry has proven to be a powerful tool of identification of drugs and their metabolites [1], the interpretation of mass spectra obtained by collisionally activated dissociation and the corresponding fragmentation patterns has become even more important. The knowledge of origin and assumed structure of fragment ions provides important information about the administered drug and its modifications, which is essential for different analytical laboratories, e.g., for those performing anti-doping, clinical, or forensic analyses. Modifications of drugs such as diuretics can be caused by metabolism [2-6] or by intentional alterations of the molecules prior to administration in order to characterize the influence of functional groups on the efficiency of the particular remedy [7-10]. For instance, the diuretic effect of chlorothiazide (6-chloro7-sulfamoyl-1,2,4-benzothiadiazine-1,1-dioxide) was increased by a factor of 10 by the hydration of its $\mathrm{N}-3=\mathrm{C}-4$ double bond to hydrochlorothiazide (6-chloro-7-sulfamoyl-3,4-dihydro-1,2,4-benzothiadiazine-1,1-dioxide) [11-13], and the substitution of a 2,6-dimethylanilide

Published online May 12, 2003

Address reprint requests to Dr. M. Thevis, Institute of Biochemistry, German Sport University Cologne, Carl-Diem Weg 6, 50933 Cologne, Germany. E-mail: m.thevis@biochem.dshs-koeln.de residue by a 2,6-dimethylpiperidyl group and a hydroxyl group by a hydrogen changes the diuretic agent xipamide to clopamide (Figure 1). The identification of structural deviations can be accomplished by means of different ionization techniques such as electron impact ionization (EI) [14-16] or electrospray ionization (ESI) [17-19], followed by MS-MS experiments with efficient collision-activated dissociation (CAD), generating structure informative fragment ions of the analytes. With negative electrospray ionization, the location of hydrogen abstraction has a significant influence on the subsequent dissociation of the deprotonated molecule, and thus on the fragmentation pattern, which provides fundamental information about the molecule. In general, fragmentation of charged molecules generated by protonation or deprotonation of analytes can undergo charge-driven and/or charge-remote fragmentations. The latter one requires a considerable activation, e.g., by CAD, as the soft ionization by means of ESI rarely introduces sufficient energy to initiate rearrangements followed by molecule dissociation [20]. Charge-remote fragmentation in particular provides detailed and specific information on molecule structures as demonstrated in the literature for several classes of compounds [21-23].

In the present study, we investigated the effect of 


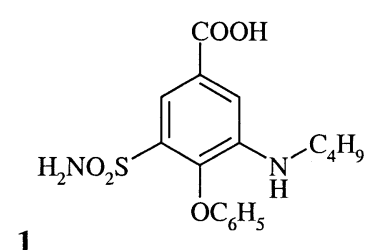

1<smiles>CCCCOc1c(N2CCCC2)cc(C(=O)O)cc1S(N)(=O)=O</smiles>

2<smiles>N#Cc1cc(C(=O)O)c(NCc2ccco2)cc1Cl</smiles>

3<smiles>NS(=O)(=O)c1cc(C(=O)O)ccc1Cl</smiles><smiles>Cc1cccc(C)c1NC(=O)c1cc(S(N)(=O)=O)c(Cl)cc1O</smiles>

5<smiles>Cc1cc(C)c(NC(=O)c2ccc(Cl)c(S(N)(=O)=O)c2)c(C)c1</smiles>

6<smiles>NS(=O)(=O)c1cc(C(=O)Nc2cccc(Cl)c2)ccc1Cl</smiles><smiles>[2H]c1c([2H])c([2H])c(NC(=O)c2ccc(Cl)c(S(N)(=O)=O)c2)c([2H])c1[2H]</smiles>

8<smiles>CC1Cc2ccccc2N1NC(=O)c1ccc(Cl)c(S(N)(=O)=O)c1</smiles>

9<smiles>CC1CCCC(C)N1NC(=O)c1ccc(Cl)c(S(N)(=O)=O)c1</smiles>

10<smiles>[R]OS(=O)(=O)c1cc(C(=O)NN([R])c2ccccc2)ccc1Cl</smiles><smiles>[R]N(NC(=O)c1ccc(Cl)cc1)c1ccccc1</smiles>

12<smiles>[R]N(NC(=O)c1ccccc1)c1ccccc1</smiles>

13

Figure 1. Structure formulae of diuretics and synthesized analogues: 1 bumetanide; 2 piretanide; 3 furosemide; 4 4-chloro-3-sulfamoylbenzoic acid; 5 xipamide; $6 \mathrm{~N}$-(4-chloro-3-sulfamoylbenzoyl)-2,4,6trimethylaniline; $7 \mathrm{~N}$-(4-chloro-3-sulfamoylbenzoyl)-3-chloraniline; $8 \mathrm{~N}$-(4-chloro-3-sulfamoylbenzoyl)-2,3,4,5,6-pentadeuteroaniline; 9 indapamide; 10 clopamide; $11 \mathrm{~N}$-(4-chloro-3-sulfamoylbenzoyl$N$-phenylhydrazine; $12 \mathrm{~N}$-(4-chloro-benzoyl)- $N$ '-phenylhydrazine; $13 \mathrm{~N}$-benzoyl- $N$ '-phenylhydrazine. $\mathrm{R}=\mathrm{CH}_{3}$ or $\mathrm{R}=\mathrm{H}$.

structural modifications of diuretics on their collisionactivated dissociation behavior, analyzed by negative electrospray ionization and tandem mass spectrometry. The presence of acidic groups such as carboxyl functions are preferred ionization sites, initiating determined fragmentation routes of the negatively charged molecule $[24,25]$. The derivatization of those functionalities to methyl esters, for instance, entails the preference of other, formerly less acidic hydrogens to be abstracted from the analyte being responsible for the generation of its anion and causing a different dissociation scheme. With diuretics, sulfamoyl residues are also frequently observed, which are targets of negative ionization as well as amide groups of several substrates. By means of selective derivatization, synthesis of labeled or modified analogues of the analytes and tandem mass spectrometry, fragmentation patterns of diuretics related to bumetanide, xipamide and indapamide were studied.

\section{Experimental}

\section{Chemicals}

Benzoyl chloride (99\%), 3-chlorobenzoic acid (99\%), 3-chloro-4-sulfamoylbenzoic acid (98\%), 3-chloro-4-sulfamoylbenzoyl chloride (99\%), 3-chloroaniline (99\%), 2,3,4,5,6-pentadeuteroaniline, 2,4,6-trimethylaniline (98\%), phenylhydrazine (97\%), and phosphorus trichloride $(99 \%)$ were purchased from Aldrich (Steinheim, Germany). N'-methyl-N'-phenylhydrazine (95\%), chlorobenzene (puriss.), triethylamine (purum), and thionyl chloride (purum) were obtained from Fluka (Buchs, Switzerland). Trimethylchlorosilane (TMCS) was supplied by Macherey-Nagel (Düren, Germany) and distilled before use. Diethyl ether (dried) and iodomethane (for synthesis) were from Merck (Darmstadt, Germany), and potassium carbonate (p.a.) was from Riedel-de Haen (Seelze, Germany). 


\section{Diuretics}

Xipamide (Aquaphor 10) was obtained from Beiersdorf (Hamburg, Germany), and Indapamide-hemihydrate (Natrilix) from Pharmacodex (München, Germany). Bumetanide was purchased from Dr. Karl Thomae GmbH (Biberach, Germany). Piretanide was supplied by Cassella-Riedel Pharma (Frankfurt, Germany), Clopamide (Brinaldix) by Sandoz (Nürnberg, Germany) and Furosemide was from Hoechst (Frankfurt, Germany).

\section{Site-Specific Methylation of Diuretics and Related Compounds}

Methylation of carboxyl groups without alkylation of primary amino groups or amide functions was accomplished by treating the substrate with anhydrous hydrogen chloride in methanol $(\mathrm{HCl} / \mathrm{MeOH})$ [26]. Briefly, a total amount of $0.1 \mathrm{mmol}$ of the particular compound was dissolved in $10 \mathrm{~mL}$ of $1 \mathrm{M} \mathrm{HCl} / \mathrm{MeOH}$ and incubated at $50{ }^{\circ} \mathrm{C}$. After $3 \mathrm{~h}$, the solution was evaporated to dryness and the residue resuspended in $10 \mathrm{~mL}$ of methanol. $\mathrm{HCl} / \mathrm{MeOH}$ was prepared by the addition of $100 \mathrm{mmol}$ trimethylchlorosilane (TMCS) to $100 \mathrm{~mL}$ of freshly distilled methanol under constant stirring for 5 $\min$.

Methylation of carboxyl and sulfamoyl groups was performed by means of iodomethane in the presence of a base [27]. Here, $0.1 \mathrm{mmol}$ of substrate were dissolved in $10 \mathrm{~mL}$ of acetonitrile, $2 \mathrm{mmol}$ of potassium carbonate and $200 \mu \mathrm{l}$ of iodomethane were added and the mixture was heated at $50^{\circ} \mathrm{C}$ under constant stirring. After $3 \mathrm{~h}$, the reaction mixture was poured through a medium porosity frit, and the solution was evaporated to dryness, yielding the methylated compound.

Hydrolysis of the resulting methyl ester was achieved by incubation of the substrate in a mixture of methanol and $0.5 \mathrm{M}$ aqueous sodium hydroxide (9:1, vol:vol) at room temperature for one $h$. The solution was evaporated to dryness, the dry residue resuspended in water and the reaction product was purified by solid-phase extraction on PAD-I polystyrene resin. Employing this method, the $m$-sulfamoylbenzoic acid derivatives (Group 1, vide infra) are obtained bearing $\mathrm{N}, \mathrm{N}$-dimethylsulfamoyl functions.

\section{Synthesis of Structural Analogues to Xipamide and Indapamide}

The synthesis of xipamide analogues was accomplished by the reaction of equal amounts $(1.3 \mathrm{mmol})$ of 3 -chloro4-sulfamoylbenzoic acid and 2,4,6-trimethylaniline, 3-chloroaniline or 2,3,4,5,6-pentadeuteroaniline suspended in $6 \mathrm{~mL}$ of chlorobenzene in the presence of 60 $\mu \mathrm{L}$ phosphorus trichloride. The mixture was incubated at $100{ }^{\circ} \mathrm{C}$ for $14 \mathrm{~h}$, filtered through a medium-porosity frit and the desired product precipitated from the cooled filtrate [28].

In order to synthesize compounds analogous to indapamide, $10 \mathrm{mmol}$ of phenylhydrazine or $\mathrm{N}^{\prime}$ methyl- $N$ '-phenylhydrazine and $15 \mathrm{mmol}$ of triethylamine were solved in $20 \mathrm{~mL}$ of diethyl ether, and the solution was added to $10 \mathrm{mmol}$ of benzoyl chloride or its appropriate derivatives (such as 3-chlorobenzoyl chloride, 3-chloro-4-sulfamoylbenzoyl chloride, and $\mathrm{N}, \mathrm{N}$-dimethyl-3-chloro-4-sulfamoylbenzoyl chloride) in $50 \mathrm{~mL}$ of diethyl ether [29]. The reaction mixture was stirred at room temperature for $14 \mathrm{~h}$, the triethylamine salts were removed by filtration, and the desired compound was obtained by evaporation of the organic solvent.

The reagents 3-chlorobenzoyl chloride, 3-chloro-4sulfamoylbenzoyl chloride and $\mathrm{N}, \mathrm{N}$-dimethyl-3-chloro4-sulfamoylbenzoyl chloride were prepared by treating $2.28 \mathrm{mmol}$ of their corresponding acids with $3.7 \mathrm{mmol}$ of thionyl chloride at $60^{\circ} \mathrm{C}$ for $4 \mathrm{~h}$. The solution was stored at room temperature for $12 \mathrm{~h}$, evaporated to dryness, and the resulting product was kept in a vacuum desiccator over phosporus pentoxide for $4 \mathrm{~h}$ before usage.

\section{Purity and Characterization of Synthesized Compounds}

Purities of synthesized compounds were tested by high performance liquid chromatography (HPLC) on a Hewlett-Packard 1090 Series II instrument equipped with a UV detector. The column used was a MachereyNagel (Düren, Germany) Nucleosil $120-5 \mathrm{C}_{18}$ with the eluent $\mathrm{A}$ : distilled water, and eluent $\mathrm{B}$ : acetonitrile. The flow was set to $1 \mathrm{~mL} / \mathrm{min}$, and a gradient was used from $10 \% \mathrm{~B}$ to $90 \% \mathrm{~B}$ in $10 \mathrm{~min}$. The analytes were dissolved in methanol at concentrations of $20 \mu \mathrm{g} / \mathrm{mL}$, and $10 \mu \mathrm{L}$ were injected into the HPLC-UV system. Purities varied from 37 to $95 \%$, and with compounds of a purity less than $70 \%$, fractions of eluting substances were collected and the isolated compounds of interest were analyzed subsequently by mass spectrometry. Impurities were identified by LC-ESI-MS and ESIMS/MS analysis primarily as starting materials, which did not interfere with the following MS/MS experiments of target compounds. Additional structure confirmation of synthesized material was accomplished by nuclear magnetic resonance spectroscopy (NMR) utilizing a Bruker DRX 500 instrument. The substances were dissolved in $\mathrm{CD}_{3} \mathrm{OD}$ or deuterated dimethyl sulfoxide (DMSO) and analyzed with different experiments, such as ${ }^{1} \mathrm{H},{ }^{13} \mathrm{C} / \mathrm{DEPT}$ (Distortionless Enhancement by Polarization Transfer), H,H-COSY (Homonuclear Correlated Spectroscopy), HMQC (Heteronuclear Multiple Quantum Correlation), NOESY (Nuclear Overhauser Effect Spectroscopy), and ROESY (Rotating Frame Nuclear Overhauser Effect Spectroscopy), at $25^{\circ} \mathrm{C}$. As all syntheses were performed according to comparable procedures and well established chemical reactions, NMR characterization was done only for five representative substances as listed in Table 1 . 
Table 1. ${ }^{13} \mathrm{C}$ chemical shifts (ppm) of synthesized compounds. All substances were dissolved in $\mathrm{CD}_{3} \mathrm{OD}$

\begin{tabular}{|c|c|c|c|c|c|}
\hline & Compound & & & & \\
\hline & $\begin{array}{l}\text { 4.2 4-Chloro-3- } N, N \text { - } \\
\text { dimethylsulfamoyl } \\
\text { benzoic acid }\end{array}$ & $\begin{array}{l}6 \mathrm{~N} \text {-(4-Chloro-3- } \\
\text { sulfamoylbenzoyl)-2,4,6- } \\
\text { trimethylaniline }\end{array}$ & $\begin{array}{l}7 N \text {-(4-Chloro-3- } \\
\text { sulfamoylbenzoyl)-3- } \\
\text { chloroaniline }\end{array}$ & $\begin{array}{l}12 N \text {-4-Chlorobenzoyl- } N \text { '- } \\
\text { phenylhydrazine }\end{array}$ & $\begin{array}{l}13 N \text {-Benzoyl- } N^{\prime} \text {-methyl- } N^{\prime} \\
\text { phenylhydrazine }\end{array}$ \\
\hline arbon $\mathrm{Nr}^{\mathrm{a}}$ & 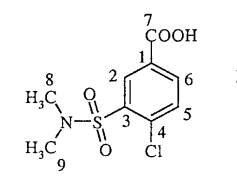 & 等 $\mathrm{NO}_{2} \mathrm{~S}$ & & 9 & 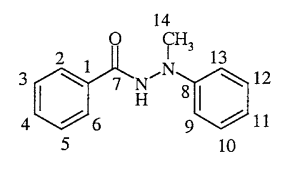 \\
\hline 1 & 131.50 & 134.73 & 135.12 & 132.82 & 134.03 \\
\hline 2 & 133.96 & 129.84 & 129.91 & 130.17 & 128.50 \\
\hline 3 & 137.78 & 142.69 & 142.52 & 129.92 & 129.78 \\
\hline 4 & 137.78 & 136.06 & 136.10 & 139.18 & 133.26 \\
\hline 5 & 133.87 & 133.14 & 133.02 & 129.92 & 129.78 \\
\hline 6 & 135.65 & 132.96 & 133.08 & 130.17 & 128.50 \\
\hline 7 & 167.30 & 166.83 & 166.37 & 169.06 & 169.43 \\
\hline 8 & 37.67 & 141.05 & 141.05 & 150.05 & 151.11 \\
\hline 9 & 37.67 & 136.71 & 120.11 & 114.20 & 114.21 \\
\hline 10 & & 129.84 & 131.13 & 130.00 & 130.07 \\
\hline 11 & & 138.45 & 125.57 & 121.19 & 120.55 \\
\hline 12 & & 129.84 & 135.40 & 130.00 & 130.07 \\
\hline 13 & & 136.71 & 121.85 & 114.20 & 114.21 \\
\hline 14 & & 18.28 & & & 40.97 \\
\hline 15 & & 21.04 & & & \\
\hline 16 & & 18.28 & & & \\
\hline
\end{tabular}

${ }^{a}$ Deviant from IUPAC, numbers are assigned for facile comparison of compounds and ${ }^{13} \mathrm{C}$ chemical shifts.

\section{Mass Spectrometry}

All MS/MS analyses were performed on a PE Sciex API 2000 triple quadrupole mass spectrometer (Foster City, $\mathrm{CA})$, while $\mathrm{MS}^{\mathrm{n}}$ experiments were done with an Agilent 1100 Series LC/MSD Trap SL (Waldbronn, Germany). Each instrument was equipped with an electrospray interface. The flow rate of the solution containing the analyte was $10 \mu \mathrm{L} / \mathrm{min}$, introduced by a syringe pump into the ESI interface. All analytes were dissolved in a mixture of acetonitrile/water (1:1, vol:vol) with a concentration of $5 \mu \mathrm{g} / \mathrm{mL}$. The ionization mode was negative and variable parameters such as declustering and focusing potentials of the triple quadrupole mass spectrometer or skimmer and capillary exit voltage of the Agilent LC/MSD were optimized for maximum abundance of the ions of interest $(\mathrm{M}-\mathrm{H})^{-}$. For the API 2000, the collision gas was nitrogen delivered by a Whatman 75-72 nitrogen generator, and a constant pressure of $1.8 \mathrm{e}-5$ torr was applied to the collision cell in MS/MS experiments. The collision offset voltage for product ion scans was varied from $15-35 \mathrm{eV}$, as indicated in Tables 2, 3, and 4. The source temperature was $30^{\circ} \mathrm{C}$, the ion spray voltage set to $-5500 \mathrm{~V}$, and nitrogen was utilized as nebulizing gas at a pressure of 20 psi.

The Ion trap was operated with helium as damping gas, and nitrogen was used as nebulizing gas for ESI.
$\mathrm{MS}^{3}$ and $\mathrm{MS}^{4}$ experiments were performed at $30{ }^{\circ} \mathrm{C}$ in order to qualitatively determine product ions of fragments observed in MS/MS spectra. Thus, precursor ions were manually selected from MS/MS experiments (4 Da window) and subsequently dissociated by resonant activation at variable fragmentor voltages (band width $10 \mathrm{Da}$ ) in order to substantiate proposed fragmentation routes.

\section{Results and Discussion}

Common structure characteristics of numerous diuretics such as 3-sulfamoylbenzoic acid derivatives [Group 1, e.g., bumetanide (1), piretanide (2), and furosemide (3)], N-(4-chloro-3-sulfamoylbenzoyl)aniline derivatives [Group 2, e.g., xipamide (5)], 4-chloro-3-sulfamoylbenzamide derivatives [Group 3, e.g., indapamide (9) and clopamide (10)], and the entire class of thiazidebased diuretics, are a benzene ring structure, bearing a sulfamoyl residue ortho-located to an electronegative substitute such as a chlorine atom or phenoxy group (Figure 1). Owing to these analogies, comparable negative ionization and subsequent CAD behaviors are observed within and also between the groups mentioned above, giving rise to mass spectra with common elimination reactions and fragment ions that are proposed to be generated by charge-driven as well as 

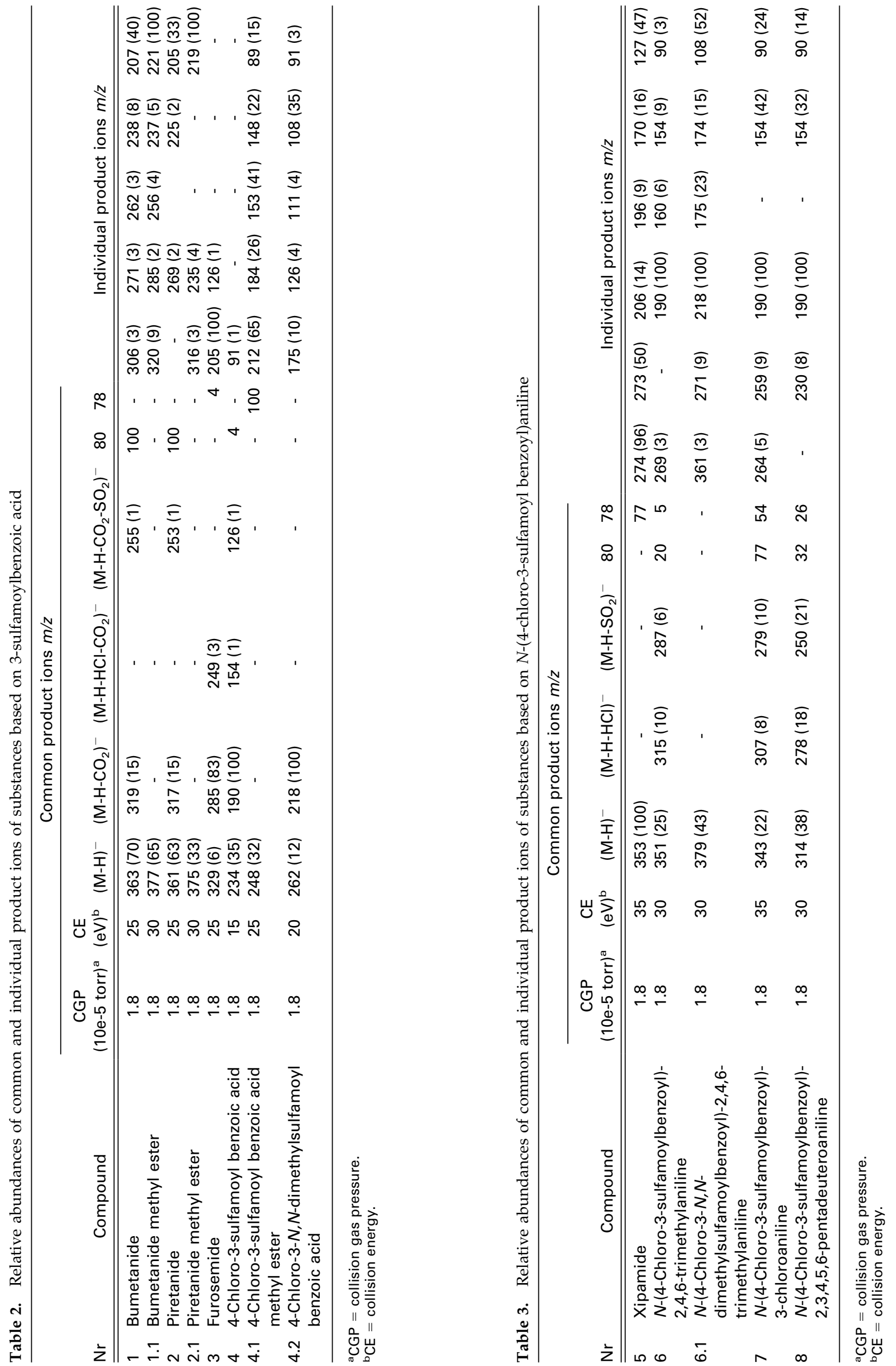


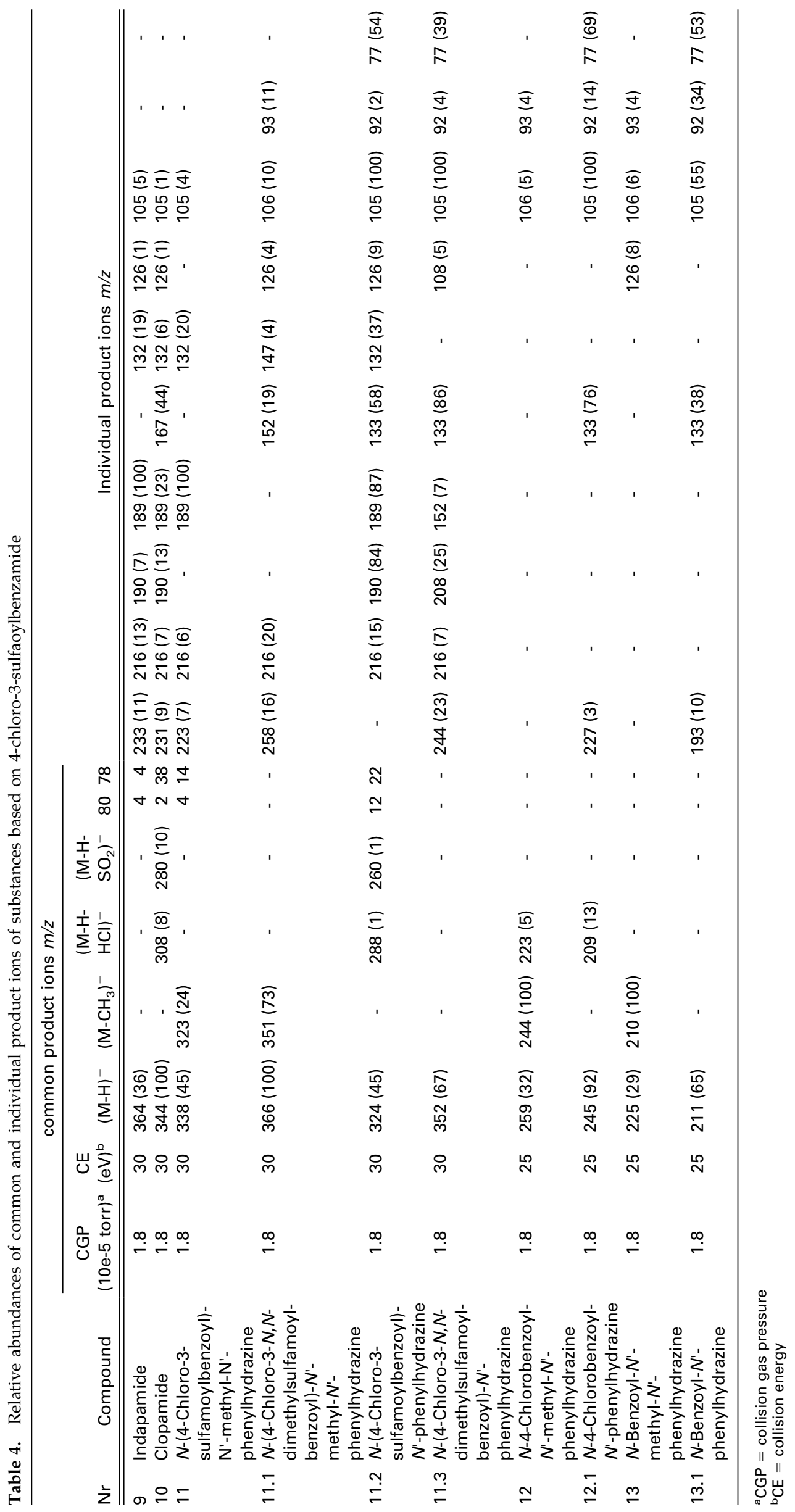



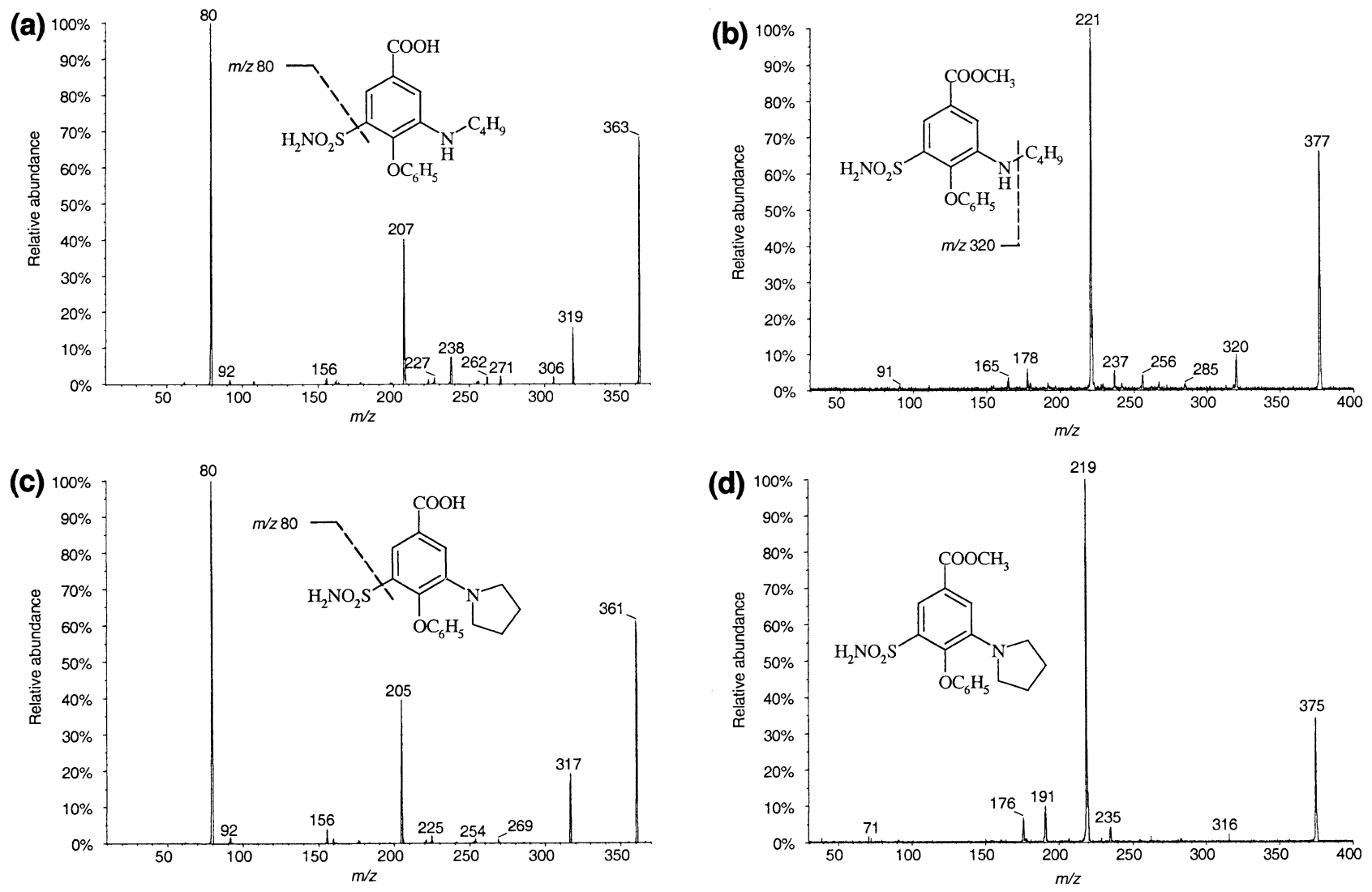

Figure 2. (a) ESI product ion spectrum of $\mathrm{m} / \mathrm{z} 363$ of bumetanide (1), $\mathrm{CE}=25 \mathrm{eV}$, collision gas pressure $=1.8 \mathrm{e}-5$ torr; $(\mathbf{b})$ ESI product ion spectrum of $\mathrm{m} / \mathrm{z} 378$ of bumetanide methyl ester (1.1), CE $=30 \mathrm{eV}$, collision gas pressure $=1.8 \mathrm{e}-5$ torr; (c) ESI product ion spectrum of $\mathrm{m} / \mathrm{z} 361$ of piretanide (2), $\mathrm{CE}=25 \mathrm{eV}$, collision gas pressure $=1.8 \mathrm{e}-5$ torr; (d) ESI product ion spectrum of $\mathrm{m} / z 375$ of piretanide methyl ester (2.1), $\mathrm{CE}=30 \mathrm{eV}$, collision gas pressure $=1.8 \mathrm{e}-5$ torr.

charge-remote fragmentation. Derivatization of these molecules in terms of ionizable hydrogens leads to significant changes of their fragmentation patterns, which enable the identification of position and character of modification. In terms of that, knowledge about origin and possible generation of individual and informative fragment ions is necessary. Thus, diuretics of closely related structures as well as compounds comparable to these diuretics, synthesized with selected modifications were analyzed, providing detailed information about ionization sites and the subsequent dissociation after collisional activation of the analytes.

\section{Group 1-3-sulfamoylbenzoic acid derivatives (Figure 1, 1-4)}

Figure 2a shows the product ion spectrum of $\mathrm{m} / \mathrm{z} 363$ of bumetanide (3-butylamino-4-phenoxy-5-sulfamoylbenzoic acid, 1), the structure of which comprises three likely locations of hydrogen abstraction with a carboxyl function, a secondary amino and a sulfamoyl group. The first-mentioned bears the most acidic hydrogen, and thus the ionization at this position is preferred over the other possibilities. The most abundant fragment ion at a collision energy of $25 \mathrm{eV}$ was $\mathrm{m} / \mathrm{z} 80$, the composi- tion of which is proposed to be $\left[\mathrm{SO}_{2} \mathrm{NH}_{2}\right]^{-}$of the sulfamoyl side chain. The generation of this ion requires the presence of a sulfamoyl group comprising two hydrogens, which indicates ionization remote from this residue, and thus the mechanism of charge-remote fragmentation. Evidence for this postulation was obtained by the analysis of the structurally related 4-chloro-3-sulfamoylbenzoic acid (Figure 1,4) under different derivatization conditions. The product ion spectrum of its deprotonated molecule, with identical collision gas pressure as chosen for Compound 1, also contains the fragment ion at $\mathrm{m} / \mathrm{z} 80$ (Table 2). With the methylation of the carboxyl group (Compound 4.1), an ionization of the resulting molecule is possible solely at the sulfamoyl residue. As a consequence, the ion at $\mathrm{m} / \mathrm{z}$ 80 disappeared, and an intense fragment ion at $\mathrm{m} / \mathrm{z} 78$ with a composition of $\left[\mathrm{SO}_{2} \mathrm{~N}\right]^{-}$(Table 2) was generated, supposably by charge-driven dissociation. The product ion spectrum obtained after selective $\mathrm{N}, \mathrm{N}$-dimethylation of the sulfamoyl group (Compound 4.2) confirms the findings, as the ion at $\mathrm{m} / \mathrm{z} 80$ (of the underivatized Compound 4) shifts to $\mathrm{m} / \mathrm{z} 108$, owing to the substitution of two hydrogens by methyl groups (Table 2). The methylation of the carboxyl group of $\mathbf{1}$ gives rise to the product ion spectrum shown in Figure $2 b$, where the 
(a)
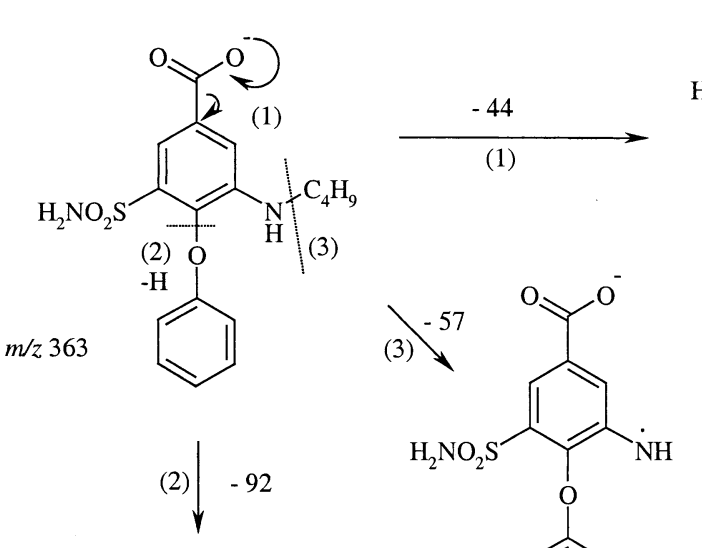<smiles>CCCCCNc1cccc(S(C)(=O)=O)c1Oc1ccccc1</smiles><smiles>CCCCCNc1cc(C(=O)[O-])cc(S(C)(=O)=O)c1</smiles><smiles>C=C(C)c1cc(N)cc(ON)c1</smiles><smiles>[3H][Mg]</smiles><smiles>[O-]c1ccccc1</smiles>

$m / z 271$<smiles>[3H][AlH2]</smiles>

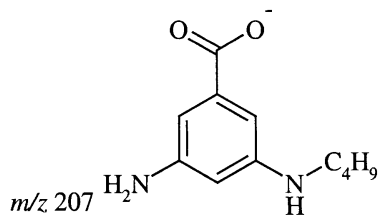<smiles>Nc1cccc(Nc2ccccc2)c1Oc1ccccc1</smiles>

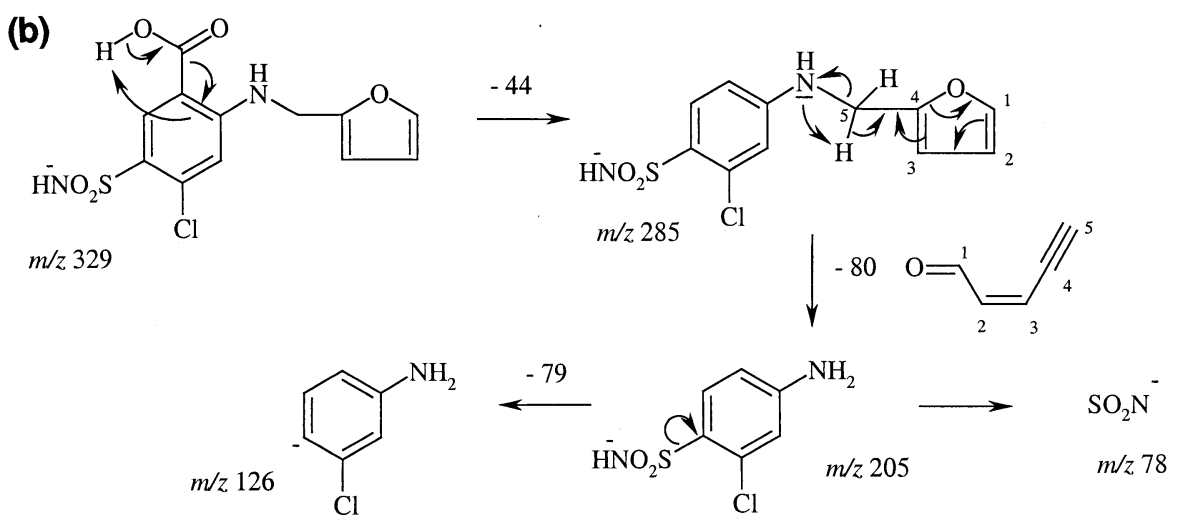

Scheme 1. (a) Postulated fragmentation of $\mathbf{1}$; (b) proposed fragmentation route of 3.

fragment ion at $\mathrm{m} / \mathrm{z} 80$ is eliminated entirely. The compound piretanide (Figure 1,2) dissociates with a fragmentation pattern comparable to that of underivatized Compound 1 (Figure 2c), with significant ions differing by 2 Da owing to the exchange of a butylamino residue by a pyrrolidinyl group. Principal eliminations besides the sulfamoyl residue of both native analytes, $\mathbf{1}$ and $\mathbf{2}$, are neutral losses of carbon dioxide $(-44 \mathrm{Da})$, sulfur dioxide $(-64 \mathrm{Da})$, and the elements of $\mathrm{C}_{6} \mathrm{H}_{4} \mathrm{O}$ ( $-92 \mathrm{Da}$, presumably the phenoxy group under migration of one hydrogen), generating their characteristic product ion spectra. Proposed fragmentation schemes for the described dissociation pro- cesses are shown in Scheme 1a. In addition, Compound 1 releases its butyl residue $(-57)$ by a homologous fission of the carbon-nitrogen bond, giving rise to the low abundant radical anion at $\mathrm{m} / \mathrm{z} 306$, and, consecutively, to the fragment at $\mathrm{m} / \mathrm{z} 262$ after loss of carbon dioxide (Scheme 1a). This particular fragmentation is not observed in the spectrum of 2 (Figure 2c), as the corresponding pyrrolidinyl residue would require the rearrangement of two single bonds under a process of ring-opening followed by the release of a $\mathrm{C}_{4} \mathrm{H}_{7}$ radical.

Another example for a diuretic agent based on the generic structure of 3-sulfamoylbenzoic acid is furosemide (Figure 1,3). Instead of a 5-positioned pyrrolidi- 
nyl or butylamino residue as present in the molecules of 2 or $\mathbf{1}$, respectively, furosemide bears a furfurylamino group, which is in the 6-position and thus located ortho to the carboxyl function. Additionally, the para phenoxy group is replaced by a chlorine atom. As a consequence, Compound 3 is closely related to 4-chloro-3-sulfamoylbenzoic acid (4), but its product ion spectrum of the deprotonated molecule $\mathrm{m} / \mathrm{z} 329$ differs significantly from 4 . Compound 3 does not give rise to the intense product ion at $m / z 80$ as found with 4 , but a fragment at $\mathrm{m} / \mathrm{z} 78$ of low abundance (Table 2). According to the data discussed above, this fact indicates a preferred ionization at the sulfamoyl residue and not at the carboxyl group, owing presumably to presence of a strong hydrogen bond with the secondary amino group present at position 6 . The entire fragmentation pattern of $\mathbf{3}$ is consistent with a hydrogen abstraction at the sulfamoyl residue followed by subsequent eliminations of $\mathrm{CO}_{2}$ (-44 Da to $\left.\mathrm{m} / z 285\right), \mathrm{C}_{5} \mathrm{H}_{4} \mathrm{O}$ of the furfuryl group ( $-80 \mathrm{Da}$ to $\mathrm{m} / z 205)$ and $\mathrm{SO}_{2} \mathrm{NH}(-79 \mathrm{Da}$ to $\mathrm{m} / \mathrm{z}$ 126) as proposed in Scheme $\mathbf{1 b}$. Here also, both charge-driven and charge-remote fragmentations are observed. While $\mathrm{CO}_{2}$ and the furfuryl group are expelled remote from the assumed ionization site, $\mathrm{m} / \mathrm{z} 78$ and 126 are generated under conditions of a chargedriven dissociation. The intermediately generated fragment ion $\mathrm{m} / \mathrm{z} 205$ and its degradation products $\mathrm{m} / \mathrm{z} 126$ and 78 (as proven with MS $^{3}$ experiments) are also postulated for the dissociation of thiazidic diuretics as described elsewhere [15].

\section{Group 2-N-(4-chloro-3-sulfamoyl benzoyl)aniline Derivatives (Figure 1, 5-8)}

A representative compound of Group 2 is the diuretic agent xipamide (4-chloro-3-sulfamoylsalicoyl-2'-6'-dimethylanilide, Figure 1, 5). It contains three eligible ionization sites including the sulfamoyl residue, the phenolic hydroxyl group at position 6 and the hydrogen of the anilide function. In Figure 3a, the product ion spectrum of the deprotonated molecule $\mathrm{m} / \mathrm{z} 353$ of $\mathbf{5}$ is shown, which comprises an intense fragment at $m / z$ 78, but no ion at $\mathrm{m} / \mathrm{z} 80$. Considering this indicator only, the hydrogen abstraction at the $-\mathrm{SO}_{2} \mathrm{NH}_{2}$ residue appears to be preferred over the other available ionization sites, but analyses of the synthesized analogues 6,7 , and 8 (Figure 1) provide evidence for a CAD mass spectrum of Compound 5, which is composed by fragment ions generated by the ionization of different functional groups. The fragments at $\mathrm{m} / \mathrm{z} 274$ and 273 are resulting from the neutral loss of $\mathrm{SO}_{2} \mathrm{NH}(-79 \mathrm{Da})$ and the elimination of the radical $\mathrm{SO}_{2} \mathrm{NH}_{2}(-80 \mathrm{Da})$, respectively, both of which are generated by charge-remote fragmentation from a molecule ionized at the phenolic hydroxyl group. This postulation is based on the product ion spectrum of $m / z 351$ of Compound 6 (Figure 3b), that comprises a 2,4,6-trimethylanilide group but lacks the phenolic hydroxyl function. Here, the counterparts
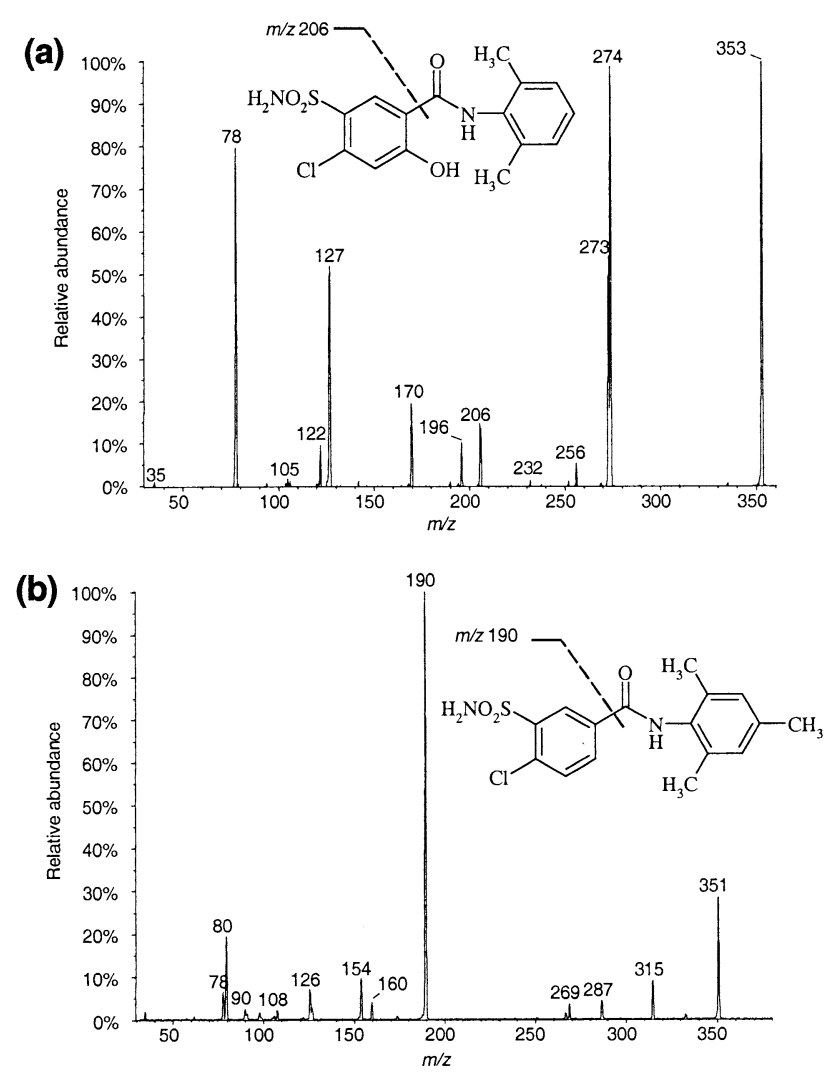

Figure 3. (a) ESI product ion spectrum of $m / z 353$ of xipamide (5), $\mathrm{CE}=35 \mathrm{eV}$, collision gas pressure $=1.8 \mathrm{e}-5$ torr; $(\mathbf{b})$ ESI product ion spectrum of $m / z 351$ of $N$-(4-chloro-3-sulfamoylbenzoyl)-2,4,6trimethylaniline (6), $\mathrm{CE}=30 \mathrm{eV}$, collision gas pressure $=1.8 \mathrm{e}-5$ torr.

to $m / z 274$ and 273 of 5 are absent (Table 3), because the ionization site required for their generation is missing. In addition, Compound 5's preferred release of the uncharged sulfonamide residue, either by neutral loss $\left(-\mathrm{SO}_{2} \mathrm{NH}\right)$ or by homologous fission of the $\mathrm{S}-\mathrm{C}$ bond between the sulfamoyl residue and the phenolic ring structure $\left(\mathrm{SO}_{2} \mathrm{NH}_{2}^{*}\right)$, explains the absence of its charged species at $\mathrm{m} / \mathrm{z} 80$. By way of contrast, the ions corresponding to $\mathrm{m} / \mathrm{z} 206$ and 170 are observed in the spectrum of Compound 6 at $\mathrm{m} / \mathrm{z} 190$ and 154, respectively (Table 3). Thus, their genesis is proposed to be charge-driven, initiated by the ionization at the amide function as demonstrated in Scheme 2 . As the fragment $\mathrm{m} / \mathrm{z} 206$ of $\mathbf{5}$ (or $\mathrm{m} / \mathrm{z} 190$ of Compound 6) comprises the chloro-sulfamoylphenol nucleus, a subsequent elimination of $\mathrm{HCl}(-36 \mathrm{Da}$ ) to $\mathrm{m} / \mathrm{z} 170$ (or $\mathrm{m} / \mathrm{z} 154$ of Compound 6) was taken into consideration, but $\mathrm{MS}^{3}$ experiments excluded this fragmentation pathway. But by means of further studies with Compound 6, the initial loss of $\mathrm{HCl}$ from the deprotonated molecule to $\mathrm{m} / \mathrm{z} 315$ was observed, giving rise to the secondary fragment ion at $\mathrm{m} / \mathrm{z} 154$, corresponding to $\mathrm{m} / \mathrm{z} 170$ of $\mathbf{5}$. Further evidence for the location of hydrogen abstraction at the amide group in case of the genesis of $\mathrm{m} / \mathrm{z} 206$ and 190 was obtained by selective methylation of the sulfamoyl residue of Compound 6 (Table 3, 6.1). Here, the nega- 
<smiles>CNS(=O)(=O)c1cc(C(=O)Nc2c(C)cccc2C)c([O-])cc1Cl</smiles><smiles>Cc1cccc(C)c1NC(=O)c1ccc(Cl)cc1[O-]</smiles>

$m / z 273$
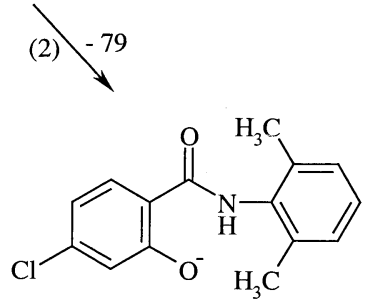

$m / z 274$
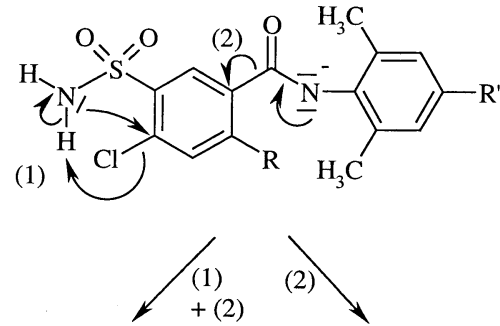

(2)

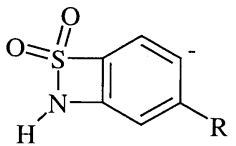

$m / z, 170 \quad \mathrm{R}=\mathrm{OH}, \mathrm{R}^{\prime}=\mathrm{H}$ $m / z 154 \quad \mathrm{R}=\mathrm{H}, \mathrm{R}^{\prime}=\mathrm{Me}$<smiles>[R]c1ccc(S(N)(=O)=O)c(Cl)c1</smiles>

$m / 206 \quad \mathrm{R}=\mathrm{OH}, \mathrm{R}^{\prime}=\mathrm{H}$ $m / z 190 \quad \mathrm{R}=\mathrm{H}, \mathrm{R}^{\prime}=\mathrm{Me}$

Scheme 2. Proposed fragmentation pattern of $\mathbf{5}$ and analogues.

tive ionization was limited to the predicted functional group, and the ion corresponding to $\mathrm{m} / \mathrm{z} 190$ (and thus to $\mathrm{m} / \mathrm{z} 206$ of Compound 5) was observed at $\mathrm{m} / \mathrm{z} 218$, according to the Biemann shift rule by the substitution of two hydrogens by $-\mathrm{CH}_{3}$ residues, proving the ionization at the amide function. However, the counterpart to $\mathrm{m} / \mathrm{z} 154$ was not detected, which indicates the necessity of the mobile nitrogen-bound hydrogens for the elimination of hydrochloric acid from the deprotonated molecule. The presence of $\mathrm{m} / \mathrm{z} 80$ in the product ion spectrum of Compound 6 also indicates ionization different from the sulfonamide group, and in addition, its selective methylation (6.1) yields an intense fragment at $\mathrm{m} / \mathrm{z} 108$ $(m / z 80+28 \mathrm{Da})$. By contrast, the ion at $m / z 106$, the counterpart to $\mathrm{m} / \mathrm{z} 78$, was not detected (Table 3).

The analysis of the synthesized analogue Compound 7 confirmed the described ionization and dissociation properties by basically identical gas-phase behaviors with Compounds 5 and 6 (Table 3). The presence of a 3-chlorophenyl residue instead of 2,4,6-trimethylphenyl or 2,6-dimethylphenyl anilide did not influence the fragmentation route, and the substitution by a 2,3,4,5,6pentadeuterophenyl residue (Compound 8) also supported the interpretation of ionizations remote from the anilidic phenol group. No evidence for the participation of deuteria in elimination or ionization processes was observed.

\section{Group 3-4-Chloro-3-Sulfamoyl Benzamide Derivatives (Figure 1, 9-13)}

This group includes the diuretics clopamide (1-(4chloro-3-sulfamoylbenzamido)-2,6-dimethylpiperidine, Figure 1,10$)$ and indapamide (N-(4-chloro-3-sulfamoylbenzamido)-2-methylindoline, Figure 1, 9), the latter one of which will be discussed in detail. In Figure 4a, the product ion scan of the deprotonated molecule of 9 $\mathrm{m} / \mathrm{z} 364$ is shown, which comprises ions at $m / z 233,216$, 189,80 , and 78 , for instance. The molecule of indapam- ide contains two ionization sites with the sulfamoyl residue and the amide functionality. Considering the presence of $m / z 78$ and 80, a fragmentation initialized by hydrogen abstraction at both groups is possible, the effects of which were investigated in terms of subsequent collision-activated dissociation. In order to compare the spectrum of Compound 9 (Figure 4a) with those obtained after selective modification of functional groups, removal and addition of particular pieces of the molecule, the Compounds 11, 12, and 13 (Figure 1) were
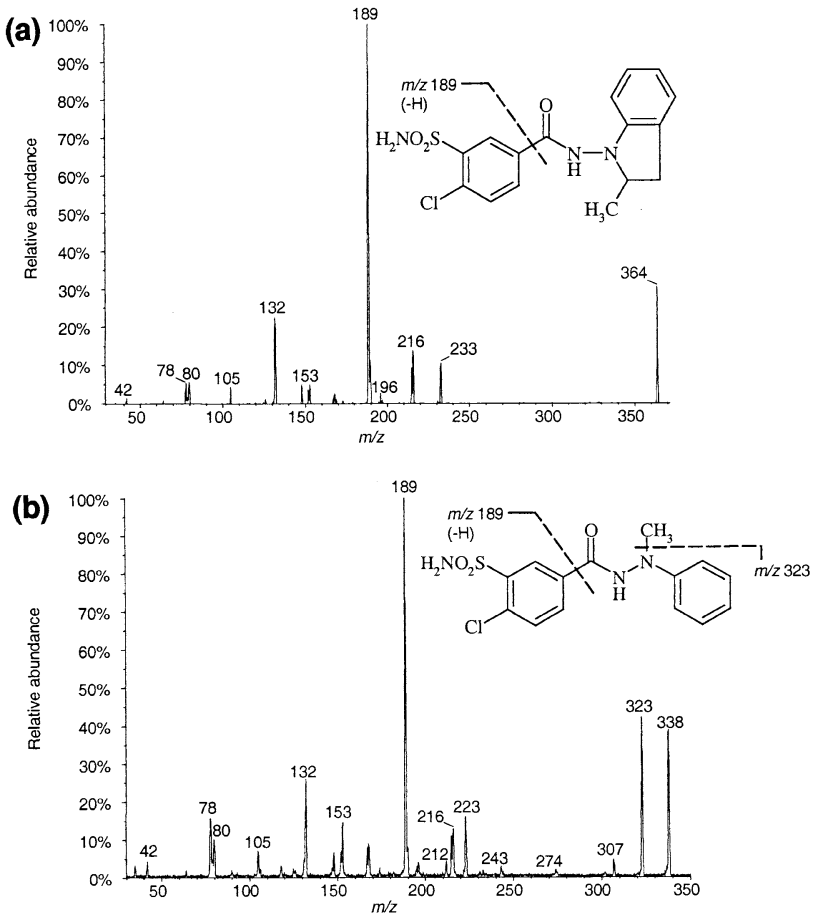

Figure 4. (a) ESI product ion spectrum of $\mathrm{m} / \mathrm{z} 364$ of indapamide (9), $\mathrm{CE}=30 \mathrm{eV}$, collision gas pressure $=1.8 \mathrm{e}-5$ torr; (b) ESI product ion spectrum of $\mathrm{m} / \mathrm{z} 338$ of $\mathrm{N}$-(4-chloro-3-sulfamoylbenzoyl)- $N$ '-methyl- $N$ '-phenylhydrazine (11), $\mathrm{CE}=30 \mathrm{eV}$, collision gas pressure $=1.8 \mathrm{e}-5$ torr. 


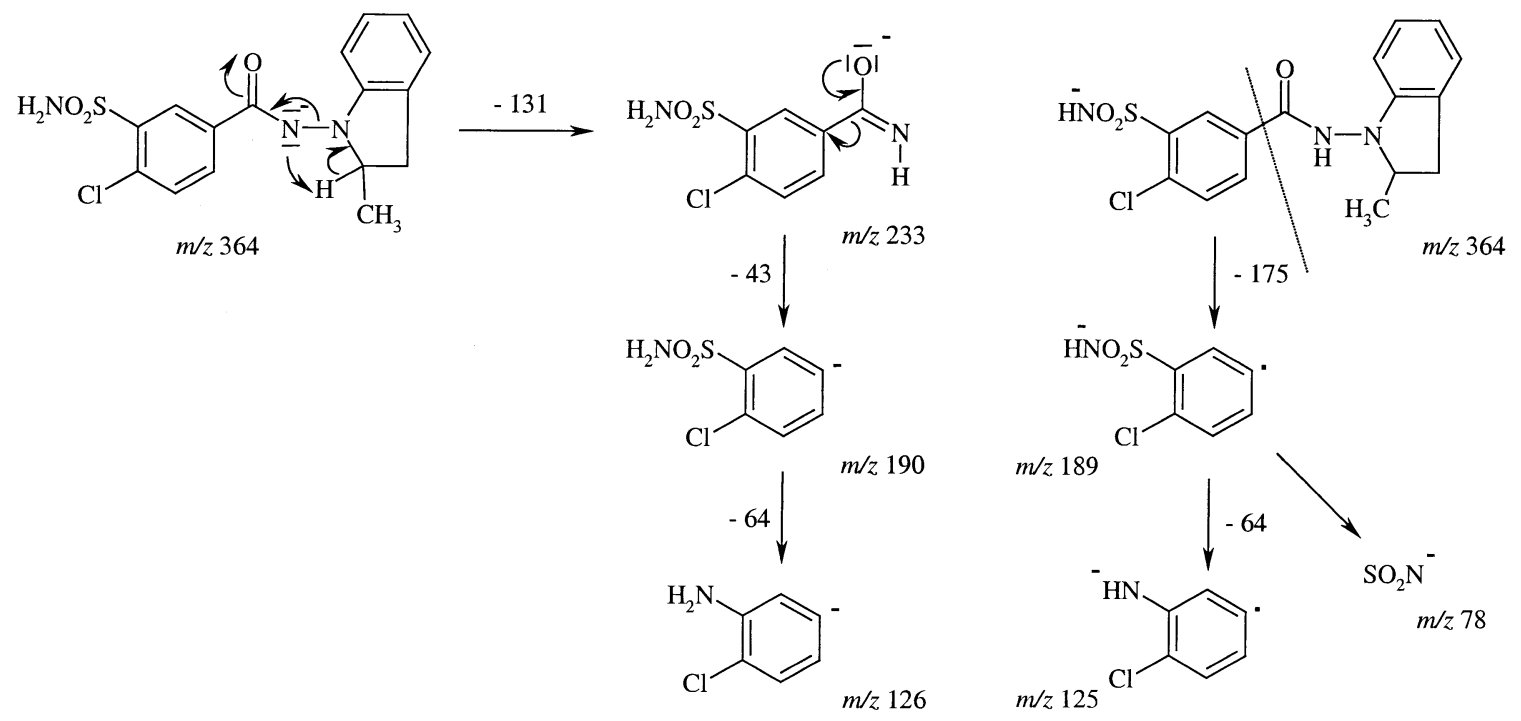

Scheme 3. Proposed fragmentation routes of $\mathbf{9}$.

synthesized and analyzed under comparable conditions as 9 (Table 4). The product ion spectrum of Compound $\mathbf{1 1}$ is shown in Figure $4 \mathrm{~b}$ containing identical fragment ions as 9 except for $\mathrm{m} / \mathrm{z} 223$ and 323. The latter ion results from an elimination of a methyl radical at the methylanilide residue, the counterpart of which was not detectable with indapamide as the particular nitrogen was part of the indoline structure.

The ion at $m / z 233$ of Compound 9 is proposed to be generated by an ionization at the amide group and subsequent neutral loss of the 2-methylindoline group accompanied by a hydrogen migration as postulated in Scheme 3. Indication for this proposal was obtained by a CAD mass spectrum of $m / z 233$, which gave rise to the fragment ions $\mathrm{m} / \mathrm{z} 190$ after loss of HNCO, iminomethanone, (-43 Da) and $\mathrm{m} / \mathrm{z} 126$ after consecutive elimination of sulfur dioxide, $(-64 \mathrm{Da})$. Furthermore, it contained the fragment $\mathrm{m} / \mathrm{z} 80$, originating from a sulfamoyl residue without deprotonation.

For the generation of the fragment $\mathrm{m} / \mathrm{z} 189$ of Compound 9, ionization at the sulfamoyl function is postulated followed by a homologous fission of the $\mathrm{C}-\mathrm{C}$ bond between the 4-chloro-3-sulfamoylphenolic structure and the amide group in accordance to a charge-remote fragmentation (Scheme 3). With Compound $\mathbf{5}$ and its analogues of Group 2 (Compound 6 and 7), the counterpart to $\mathrm{m} / \mathrm{z} 189$ was observed at $\mathrm{m} / \mathrm{z} 206$ or 190, respectively, as a result of ionization remote from the sulfamoyl residue. With indapamide, hydrogen abstraction occurs intensively at this particular functionality, yielding immediately $m / z 189$, as a precursor ion scan did not give rise to any other intermediate ion. As a confirmation of composition, the CAD of $\mathrm{m} / \mathrm{z} 189$ generated the fragments $m / z 125$ after loss of $\mathrm{SO}_{2}(-64 \mathrm{Da}$ ) and $m / z 78\left(\mathrm{SO}_{2} \mathrm{~N}^{-}\right)$, but no $\mathrm{m} / \mathrm{z} 80$ as its production is depending on an intact sulfamoyl residue. In addition, the methylation of the sulfamoyl group of Compound 11 (Table $4,11.1$ ) limited the possibility of negative ionization to the amide group under the chosen conditions. Thus, $\mathrm{m} / \mathrm{z} 189$ or its corresponding ion at $\mathrm{m} / \mathrm{z} 207$ $(+28 \mathrm{Da})$ were not observed in a product ion spectrum of $m / z 366$ (Table 4), proving the necessity of an ionization at the sulfamoyl residue for a radicalic release of the 4-chloro-3-sulfamoylphenol anion.

Compound $\mathbf{1 2}$ is the analog of $\mathbf{1 1}$ minus the sulfamoyl group, the product ion spectrum of which contains mainly the fragments resulting from the elimination of a methyl radical or $\mathrm{HCl}$ (Table 4). Also the CAD spectrum of Compound 13, which additionally lacks the chlorine atom at the benzoyl residue, does not yield more informative ions of the analytes (Table 4). But the introduction of a new ionization site by substitution of the nitrogen-bound methyl group by a hydrogen (Table $4,13.1$ ) enables different fragmentation pathways, giving rise to the mass spectrum shown in Figure 5a. With all abundant product ions such as $\mathrm{m} / \mathrm{z} 133,105,92$ and 77 , the negative charge remains remote of the benzoyl residue as demonstrated with the postulated structures in Scheme 4. Evidence for the presence of the anilide group instead of the benzamide functionality was obtained by the analysis of Compound 12.1, also bearing a hydrogen at the anilide functionality (Table 4 ). Here, the chlorine atom at the benzamide residue would shift the fragment ions by 34 mass units, if they would comprise this part of the molecule. As shown in Figure $5 \mathrm{~b}$, the specified product ions are not affected, which proves their composition without the 4-chlorobenzoyl nucleus. With the introduction of a 3-sulfamoyl residue into Compound 12.1, we obtained Compound 11.2, which gives rise to the product ion spectrum shown in Figure 5c. It contains abundant fragments at $m / z 133$, 105, and 77 as observed already in Compound 13.1, and additionally intense ions known from Compound 9 such as $m / z 216,190,189,126,80$, and 78 . Here, a typical mass spectrum is generated by collision-activated dissociation that comprises fragment ions originating from 

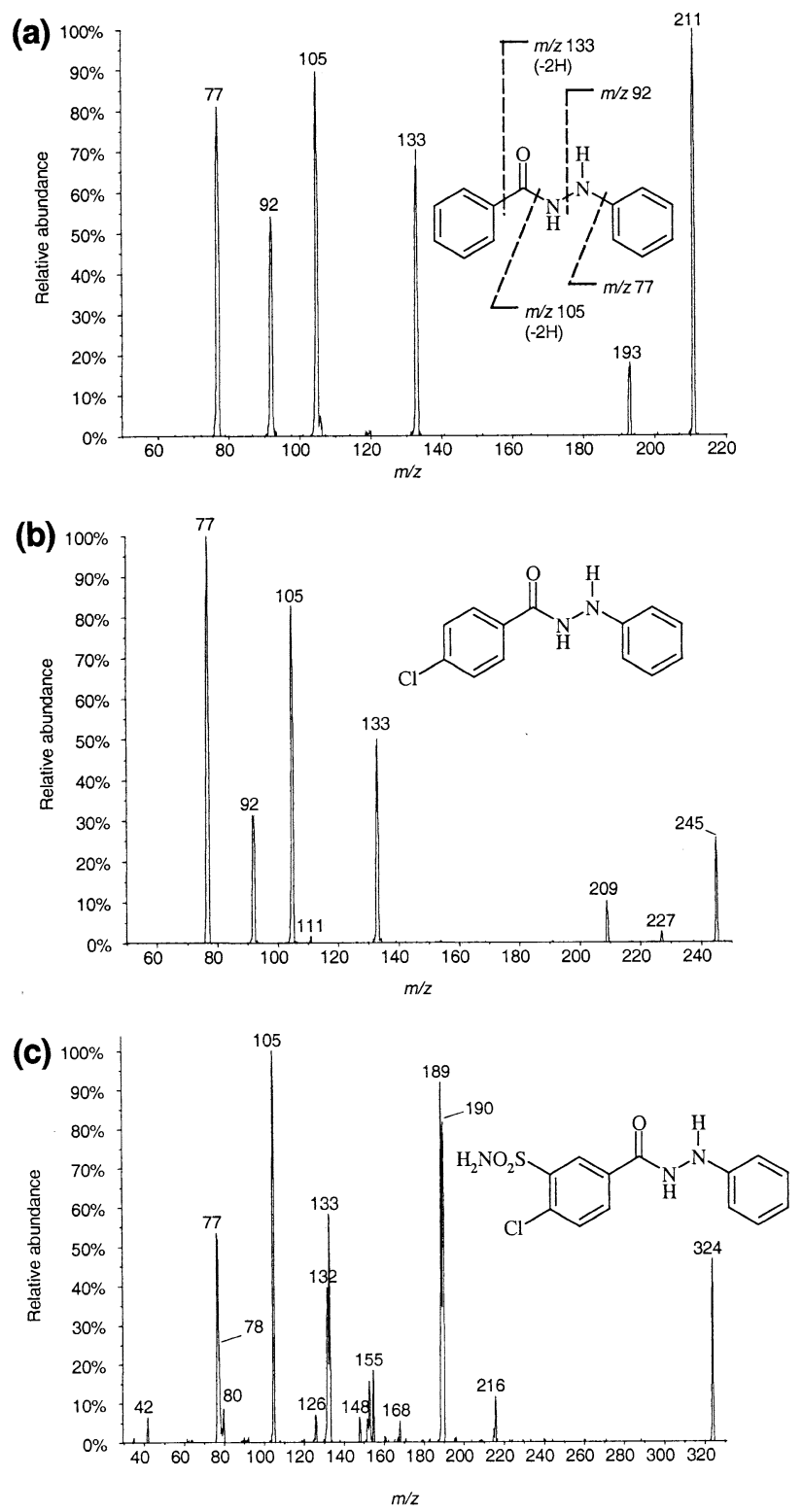

Figure 5. (a) ESI product ion spectrum of $N$-benzoyl- $N$ '-phenylhydrazine (13.1), $\mathrm{CE}=25 \mathrm{eV}$, collision gas pressure $=1.8 \mathrm{e}-5$ torr; (b) ESI product ion spectrum of $N$-(4-chlorobenzoyl)- $N$ '-phenylhydrazine (12.1), $\mathrm{CE}=25 \mathrm{eV}$, collision gas pressure $=1.8 \mathrm{e}-5$ torr; (c) ESI product ion spectrum of $\mathrm{N}$-(4-chloro-3-sulfamoyl benzoyl)$N$-phenylhydrazine (11.2), $\mathrm{CE}=30 \mathrm{eV}$, collision gas pressure $=$ $1.8 \mathrm{e}-5$ torr.

different ionization sites and subsequent fragmentation pathways. Again, selective methylation of the sulfamoyl function (Table 4, 11.3) eliminates the fragments at $m / z 189$ and 78 , but gives rise to the counterpart of $m / z 80$ at $m / z$ 108. The ions at $m / z 216,133,105$, and 77 are still present, indicating their generation independent from an ionization of the molecule at the sulfamoyl residue.

\section{Conclusion}

The location of ionization plays an important role on the collision-activated dissociation of compounds based

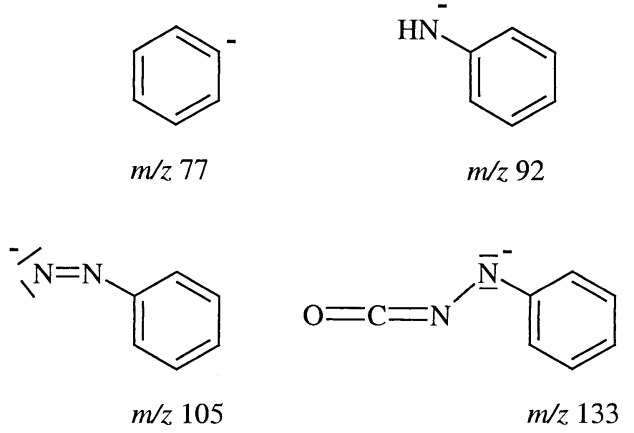

Scheme 4. Postulated structures of fragment ions of N-benzoyl$N$-phenylhydrazine (13.1) and analogues.

on the structure of the diuretic agents bumetanide (1), xipamide (5), and indapamide (9). Indication for ionization at the sulfamoyl residue is obtained by the product ion at $m / z 78$, but its presence does not exclude necessarily other sites of hydrogen abstraction, as shown for example with xipamide. Minor or major modifications of analytes can introduce or eliminate positions of ionization, and thus severely change and influence resulting CAD spectra. With these deviations, important information about character and also location of derivatization are provided. In addition, the frequent generation of radical anions is noteworthy, despite the commonly accepted "even-electron-rule". Although the majority of observed elimination reactions happened in accordance to this rule, the presence of spacious conjugated $\pi$-electron systems amplifies the homologous fission of carbon-carbon bonds and the stabilization of resulting radical anions. This fact should be considered by interpretations of mass spectra of compounds related to the analytes investigated in this study.

\section{Acknowledgments}

The authors acknowledge financial support from the Bundesinstitut für Sportwissenschaft, Bonn.

\section{References}

1. Gelpi, E. Biomedical and Biochemical Applications of Liquid Chromatography-Mass Spectrometry. J. Chromatogr. A 1995, 703, 59-80.

2. Campbell, D. B.; Taylor, A. R.; Hopkins, Y. W.; Williams, J. R. B. Pharmacokinetics and Metabolism of Indapamide: A Review. Curr. Med. Res. Opin. 1977, 5 (Suppl. 1), 13-24.

3. Hempelmann, F. W.; Dieker, P. Untersuchungen mit Xipamid (4-chlor-5-sulfamoyl-2',6'-salicyloxylidid). Teil II: Pharmacokinetik beim Menschen. Drug Res. 1977, 27, 2143-2151.

4. Smith, D. E.; Lin, E. T.; Benet, L. Z. Absorption and Disposition of Furosemide in Healthy Volunteers, Measured with a Metabolic-Specific Assay. Drug Metab. Dispos. 1980, 8, 337-342.

5. Halladay, S. C.; Sipes, E. G.; Carter, D. E. Diuretic Effect and Metabolism of Bumetanide in Man. Clin. Pharmacol. Ther. 1978, 22, 179-187.

6. Möhrke, W.; Ullrich, F. Metabolism of Diuretics. In Handbook of Experimental Pharmacology; Vol CXVII; Greger, R. F.; Knauf, H.; Mutschler, E., Eds.; Springer-Verlag: Berlin/New York, 1995; pp 173-200. 
7. Wilhelm, M.; deStevens, G. Antihypertensive Agents. Prog. Drug. Res. 1976, 20, 197-259.

8. Lang, H.-J.; Hropot, M. Discovery and Development of Diuretic Agents. In Handbook of Experimental Pharmacology; Vol CXVII; Greger, R. F.; Knauf, H.; Mutschler, E., Eds.; SpringerVerlag: Berlin/New York, 1995; pp 141-172.

9. Nishijima, K.; Nishida, H.; Yamashita, Y.; Ito, M.; Onuki, Y.; Mizota, M.; Miyano, S. Synthesis and Diuretic Activity of Bicyclic Fused Heterocycles Containing Oxime-O-Sulfonic Acid Moiety. Eur. J. Med. Chem. 2000, 35, 227-240.

10. Hunt, C. A.; Mallorga, P. J.; Michelson, S. R.; Schwam, H.; Sondney, J. M.; Smith, R. L.; Sugrue, M. F.; Shepard, K. L. 3-Substituted Thieno(2,3-b)(1,4)thiazine-6-sulfonamides. A Novel Class of Topically Active Carbonic Anhydrase Inhibitors. J. Med. Chem. 1994, 37, 240-247.

11. deStevens, G.; Werner, L. H.; Halamandaris, A.; Ricca, S. Dihydrobenzothiadiazine Dioxides with Potent Diuretic Effect. Experientia 1958, 14, 463.

12. Werner, L. H.; Halamandaris, A.; Ricca, S.; Dorfman, L.; deStevens, G. Dihydrobenzothiadiazine 1,1-Dioxides and Their Diuretic Properties. J. Am. Chem. Soc. 1960, 82, 11611166.

13. Sherlock, M. H.; Sperber, N.; Topliss, J. 3-Haloalkyl-Dihydrobenzothiadiazine Dioxides as Potent Diuretic Agents. Experientia 1960, 16, 184-185.

14. Schänzer, W. The Problem of Diuretics in Doping Control. Proceedings of the International Athletic Foundation World Symposium on Doping in Sport; Bellotti, P.; Benzi, G.; Ljungqvist, A., Eds.; Florence, Italy, 1987; pp 89-106.

15. Lisi, A. M.; Trout, G. J.; Kaslauskas, R. Screening for Diuretics in Human Urine by Gas Chromatography-Mass Spectrometry with Derivatisation by Direct Extractive Alkylation. J. Chromatogr. 1991, 563, 257-270.

16. Maurer, H. H. Systematic Toxicological Analysis Procedure for Acidic Drugs and/or Metabolites Relevant to Clinical and Forensic Toxicology and/or Doping Control. J. Chromatogr. B 1999, 733, 3-25.

17. Thevis, M.; Schmickler, H.; Schänzer, W. Mass Spectrometric Behavior of Thiazide-Based Diuretics after Electrospray Ionization and Collision-Induced Dissociation. Anal. Chem. 2002, 74, 3802-3808.
18. Garcia, P.; Popot, M.-A. Fournier F.; Bonnaire Y.;; Tabet, J. C. Gas-Phase Behavior of Negative Ions Produced from Thiazidic Diuretics under Electrospray Conditions. J. Mass Spectrom. 2002, 37, 1765-1769.

19. Thieme, D.; Grosse, J.; Lang, R.; Mueller, R. K.; Wahl, A. Screening, Confirmation and Quantitation of Diuretics in Urine for Doping Control Analysis by High-Performance Liquid Chromatography-Atmospheric Pressure Ionization Tandem Mass Spectrometry. J. Chromatogr. B 2001, 757, 49-57.

20. Gross, M. L. Charge-Remote Fragmentation: Method, Mechanism and Applications. Int. J. Mass Spectrom. Ion. Processes 1992, 118/119, 137-165.

21. Tomer, K. B.; Crow, F. W.; Gross, M. L. Location of Double Bond Position in Unsaturated Fatty Acids by Negative Ion MS/MS. J. Am. Chem. Soc. 1983, 105, 5487-5488.

22. Chen, G.; Pramanik, B. N.; Bartner, P. L.; Saksena, A. K.; Gross, M. L. Multiple-Stage Mass Spectrometric Analysis of Complex Oligosaccharides Antibiotics (Everninomicins) in a Quadrupole Ion Trap. J. Am. Soc. Mass Spectrom. 2002, 13, 1313-1321.

23. Cheng, C; Gross, M. L. Applications and Mechanisms of Charge-Remote Fragmentations. Mass Spectrom. Rev. 2000, 19, 398-420.

24. Bowie, J. H. The Formation and Fragmentation of Negative Ions Derived from Organic Molecules. Mass Spectrom. Rev. 1984, 3, 161-207.

25. Bowie, J. H. The Fragmentation of Even-Electron Organic Negative Ions. Mass Spectrom. Rev. 1990, 9, 349-379.

26. Hulshoff, A.; Förch, A. D. Alkylation with Alkyl Halides as Derivatization Method for the Gas Chromatographic Determination of Acidic Pharmaceuticals. J. Chromatogr. 1981, 220, 275-311.

27. Dünges, W. Alkylation of Acidic Organic Compounds for Gas Chromatographic Analysis. Chromatographia 1973, 6, 196-197.

28. Liebenow, W.; Leuschner, F. Struktur-Wirkungsbeziehungen beim Diuretikum Xipamid (4-chlor-5-sulfamoyl-2',6'-salicyloxylidid). Arnzeim. Forsch. 1975, 25, 240-244.

29. Landriani, L.; Barlocco, D.; Pinna, G. A.; Demontis, M. P.; Miele, M.; Enrico, P.; Anania, V. Diuretic Agents Related to Indapamide. Farmaco 1989, 44, 1059-1068. 